\title{
Enhancing Interpersonal Intelligence for Management Educators
}

\author{
Najib Ahmad Marzuki ${ }^{1} \&$ Halimah Abdul Manaf ${ }^{2}$ \\ ${ }^{1}$ School of Social Development, College of Arts and Sciences, Universiti Utara Malaysia, Sintok, Kedah, \\ Malaysia \\ ${ }^{2}$ School of Government, College of Law, Government and International Studies, Universiti Utara Malaysia, \\ Sintok, Kedah, Malaysia \\ Correspondence: Najib Ahmad Marzuki, School of Social Development, College of Arts and Sciences, Universiti \\ Utara Malaysia, Sintok 06010, Kedah, Malaysia. Tel: 60-13-430-0770. E-mail: najib320@uum.edu.my
}

Received: April 10, 2014 Accepted: May 16, 2014 Online Published: May 27, 2014

doi:10.5539/res.v6n2p104 URL: http://dx.doi.org/10.5539/res.v6n2p104

\begin{abstract}
Management education is not a rare domain anymore. People learn, study and teach management in a diversity of branches of knowledge or disciplines. In this perspective, management educators are required to be people-smart. The ability to administer their inner feelings as well as to work with people will improve the quality and effectiveness of management teaching. To reach this, personal intelligences which include general intelligence (Intelligence Quotient $\{\mathrm{IQ}\}$ ), emotional intelligence (Emotional Quotient $\{\mathrm{EQ}\}$ ) and interpersonal intelligence (People Quotient $\{\mathrm{PQ}\}$ ) are essential. . This paper will tackle the issue of enhancing interpersonal intelligence (PQ), which also takes into account the aspect of emotional intelligence (EQ) among management educators. To ensure success in interpersonal intelligence, several criteria can well predict people's quotient. These are the ability to understand students, the ability to grasp people/students' ability to clearly establish thoughts and feelings, ability to ask and offer feedback, ability to serve as a determinant to how others act and think, ability to engage in and resolve conflicts, and, ability to work with others effectively. It is anticipated that management education will not only perform well in the content and structure but in the psychological aspects of management educators as well.
\end{abstract}

Keywords: intelligence, emotional, interpersonal, management

\section{Introduction}

One of the main resources in higher education institution is the academic staff. The academic staff, in particular, makes up a substantial component of higher education institutions and they serve to meet the objective of the institutions. Their roles as lecturers and researchers and also as managers, determine, in a major way, the quality of student experiences of higher education and its corresponding significant impact on student learning and further, on the contribution made by the institutions to the society.

To date, there are multiple disciplines in which students learn and study management. Therefore, the importance of the student/lecturer interface cannot be denied in ascertaining the quality, and it is thought to be suitable to monitor this quality through efficient quality assurance processes (Cornersky, 1991; Janis \& Holly, 2005). Nevertheless, reality has it that the quality assurance processes are superficial by nature. The real challenge lies in the area of quality enhancement (Afolabi, Okediji \& Ogunmwonyi, 2009; Rowley,1996). It originates from the self-awareness of the nature of being good management educators. This is where personal intelligence comes into the picture.

While students are offered high quality learning experience, most higher education institutions can have either an implicit or explicit mission. Academic staff or lecturers normally supervise this learning experience and automatically function as the main interface with students. Well-motivated academic staff can develop good personal intelligence, given appropriate support. Managing inner feeling and being able to work well with students will improve the quality and effectiveness of management teaching

It has been a while that psychologists, educators, and other professionals come to know what distinguishes the average, from the shining performers. The technical skills or general intelligence does not cut it. It is something else that is very abstract, something that we know once we see it but find it hard to define it. This is called the people skills. Therefore, we called it personal intelligence since it has a direct link with the self or individual. 
The concept of personal intelligence covers several elements. It includes general intelligence, emotional intelligence and interpersonal intelligence. However, this paper will only dwell into the issue of interpersonal intelligence which also include emotional intelligence as a fraction of educators' psychological self-construct.

\subsection{What is Emotional and Interpersonal Intelligence?}

There is a powerful argument raised by Goleman (1996) and Killian (2012) that our intelligence in managing ourselves emotionally and our relationship may emerge as the best predictors of life success. When selecting a job, our intellectual intelligence might get us employed, but it is our emotional intelligence that will take us up the promotional ladder. How we take control of our emotions and collaborate with others is becoming more and more crucial in organizations today. Our emotional intelligence facilitates us in thinking more clearly and creatively. The way the brain frees cortical inhibitors that spark the connection between the emotional brain and the thinking brain when we happen to be restless, frustrated and furious is somehow both psychological and physiological in nature.

Therefore, emotional intelligence is the ability to perceive, access and generate emotions in order to form thoughts, to grasp the emotions and emotional knowledge and to regulate emotions that can fuel emotional and intellectual growth reflectively (Mayer \& Salovey, 1997; Wong \& Law, 2002). It actually marries two of the three states of mind, namely cognition and affective (intelligence), and emotion. Furthermore, emotional intelligence demonstrates the skills as listed below:

Identifying emotions - the ability to identify how you and those around you are feeling

Using emotions to facilitate thought - the ability to create an emotion, and the reason accompanying this emotion.

Understanding emotions - the ability to grasp complex emotions and emotional 'chains', how emotions change from one stage to another.

Managing emotions - the ability that allows you to handle your emotions in yourself and in others.

However, one should remember that emotional intelligence does not and should not be taken as a replacement or substitute for ability, knowledge or job skills. It is hypothesized that emotional intelligence improves outcomes at the workplace but it is not guaranteed without the existence of appropriate skills (Mayer, 2001). In management development, lecturers who pay attention to their technical skills are the superior, although they are no managers. Understanding and enhancing emotional intelligence are two ways that are able to improve certain management skills and styles (Gardner, Kornhaber \& Wake, 1996).

The concept of emotional intelligence is specifically captivating. It also involves a set of skills which incorporate what is called interpersonal intelligence. A profile of these skills normally illustrates high levels of self-awareness, emotional control, integrity, initiative, influencing skills, flexibility and assertiveness.

\section{People's Quotient (PQ)}

Dealing with people (in this case students) implies that educators or lecturers have to engage themselves with a set of body with mind and soul. Therefore, a more humanistic approach is essential to ensure that quality teaching is effective. Management education is not exempted. Since the contents may be multi-disciplinary, the approach taken must ensure that it can perform the best possible technique available. However, as mentioned previously, having excellent skills does not surely lead to effectiveness. There are other requirements seeking to enhance their management teaching skills. Discussing interpersonal and emotional intelligence necessitates the understanding of people's quotient. It is a set of hypothetical measured components for these academicians to think of. Hence, what constitutes educators/lecturers' PQ?

\subsection{Ability to Understand Students}

Management educators/lecturers with high PQs are active listeners, where they empathize with students' feelings, and acknowledge his or her students' perspectives. This will not only help the students to feel valued, but it also extracts the information they need to know what is included in the self-awareness of the other person. They ask questions for clarification when confusion is in the air. They also realize that understanding others does not just mean understanding the words they speak. They should also have the capacity to interpret the unspoken. Finally, they are very good at deciphering other people's styles and motives. This is crucial in a multicultural learning environment, where interpersonal communication competence and knowledge are the basis to well-accomplished teachers (Washington, Okoro \& Okoro, 2013). 


\subsubsection{Empathy}

Empathy is the ability to perceive the world from another person's viewpoint, the capacity to tune into what someone else is possibly thinking and feeling about a situation (Gray \& Watson, 2001). It does not matter how that view might be different from their own perceptions. It is an extremely robust interpersonal tool. When educators/lecturers produce an empathic statement, even in the middle of a heated debate, they will create some kind of balance. A contentious and uneasy interchange will normally turn to be a more collaborative alliance.

The components included in empathy are:

\section{a) Put emotions on hold}

If educators/lecturers have the tendency to be temperamental, they must learn to adjust their emotional temperature before it gets uncontrollable. For example, a student speaks in a tone that can be described as rude and disrespectful. So, they must take a step back, stop and think for a while. Their student's purpose behaving as such is not to get them angry or disappointed. What is wise to do is to switch on the radar. Their anger is signified as a red light. Something is disturbing the student, and it is essential for educators/lecturers to withdraw until they are aware of what is going on. They have discerned that the student is not upsetting them, but at himself and his team for not winning. He's not angry at them but at the other team for being the champion, and at himself and his teammates for not playing well. Now, is the time for the lecturer to understand, to neutralize the confrontation rather than succumb to their own anger and allow it to rise.

There's a dual challenge here: to use self-awareness to measure their increasing irritation, contain their impulses and act sensibly in the wake of provocation, and to call upon their impulses and act sensibly in the face of provocation; and to evoke our empathy as to grasp the other person's state of being.

\section{b) Ask excavating questions}

In this part, they must know that someone understands their point of view, and feel more at home with the idea of freely venting a sense of displeasure or hurt feelings. If there is an atmosphere of distrust or a hierarchical power imbalance then calling upon their empathic abilities would be even harder.

One is led to believe that if they know a person quite well and are able to recall his thoughts and feelings as shown in previous and vaguely similar encounters, they can formulate a fairly accurate guess as to what his feelings are likely to be at the moment. However, it is not right to assume too much about anyone - especially a student. That is why unraveling questions are an important prelude to evoking empathy.

Excavating questions help unbury the truth of the matter. It uncovers another person's innermost emotions by asking him to give more information about them, information that will allow the lecturer to start responding. These questions cannot be tackled with a simple yes or no. They are personal and open-ended, although very often outwardly non-specific.

Expressing empathy requires one's emphasis on two types of information: first, the words used by the other person to elaborate on his or her thoughts and feelings. Second, the words used to elaborate on what they want or desire, and expect (McBride \& Maitland, 2002).

\section{c) Focus on the other's subjective perspective}

Factors that lead people to develop a more natural sense of empathy is the ability to ask questions that take the interchange away from the superficial concerns. It stresses on understanding about the perspectives of others, especially if they are different from our own. For example, empathic listening becomes so strong because it supplies precise data. Instead of projecting their own autobiography and assuming thoughts, feelings, movies and interpretation, they tend to administer the reality inside the other person's head and heart.

Power empathy is all about being able to grasp the thinking and feeling of the other person, even if it is very much different from their own, translate their comprehension into words, and yet he or she makes the other person feels understood. This offsets any amount of tension that exists and instead, forges a strong collaboration that helps them to obtain what they want; to solve problem and form good interpersonal relationships.

\subsubsection{Self Regard}

This is the ability to respect and accept oneself as a good person. Respecting oneself crucially means the way one is. Self-regard is the ability to value their perceived positive aspects and possibilities as well as to accept their shortcomings and limitations, and yet still accept themselves the way they are. In other words, self-regard means acknowledging one's own strengths and weaknesses.

To understand students, they must have the knowledge of how they can understand themselves. This is the way 
that self-regard function. The problem is that too highly-rated self-esteem can lead one to become boastful. Telling how great you are, may or may not be a legitimate part of an approach to repair a damaged ego, but it is not the end of the world. This is why educators and psychologists have recently started to re-evaluate the two-decade-old inculcation of self-esteem in young children that is supposed to serve as inoculation against hostile tendencies and other emotional complications.

\subsection{Ability to Express thoughts and Feelings Clearly}

Educators/lecturers must know how to deliver their messages so that the messages are totally understood. When people try to make a point, chances are that they simply leave no impact on other people. High PQ educators/lecturers will come to a point when brevity is required, yet they will provide enough details so that other people are not in the dark about it. Sensing whether other people have understood them and quickly rephrasing them are PQ skills. In addition, educators who have high PQ are able to show their feelings, live and work on their own, and that they have no qualms about sharing their ideas. The components of this ability include:

\subsubsection{Assertiveness}

Assertiveness is composed of three fundamental components: (1) the ability to express feelings; (2) the ability to show beliefs and thoughts openly and have a particular stance about something, even if it is emotionally challenging to do so and even if you are at the losing end by doing so); and (3) the ability to defend own personal rights. Assertive people are not over-controlled or shy - they are able to demonstrate their feelings (often directly) without being hostile.

\subsubsection{Self-Actualization}

It is the ability to realize one's potential capacities. This component of interpersonal intelligence is manifested by becoming engaged in endeavours leading to a meaningful, rich and full life. Striving to actualize their potential involves developing enjoyable and meaningful activities and it can indicate a lifelong effort and an enthusiastic commitment to long term goals. Self-actualization is a continuous, dynamic process of striving toward the maximum development of one's abilities and talents, of persistently trying to perform and excel, and generally improve. Excitement about one's interests can both be energizing and motivating. Self-actualization is typically intertwined with feelings of self-satisfaction.

\subsection{Ability to Ask and Give Feedback}

High PQ educators are not secretive about their reaction to others. They are able to offer feedback easily and do it in a manner whereby the other people would not be defensive. They are aware that asking for feedback is a wise thing to do. If feedback is suspended, it is as though the person has some blinders on. Without feedback, it is not strange that they are left to wonder what the other person is thinking about you.

\subsubsection{Flexibility}

This is the ability to adapt emotions, thoughts and behavior to some changing situations and conditions. The component of interpersonal intelligence applies to the overall ability to come to terms with unfamiliar, unpredictable and dynamic conditions. Flexible people are agile, synergistic and capable of responding to change. Without being rigid, they can easily divert when proven wrong. They are generally open to, and can tolerate, a diversity of ideas and ways of others. Their ability to change their ways of thinking and behaving is rather harmonious with the feedback they are obtaining from their surroundings. Individuals, who do not have this capacity to be rigid and obstinate, adapt badly to new situations and may not be strong enough to take advantage of new opportunities. Flexibility involves the ability to train oneself to reinterpret unexpected situations that may at first inspire gloom or alarm.

\subsection{Ability to Influence How Others Act and Think}

Educators with high PQ have the ability to spur students to action. Students come for advice. They are able to relate with others, unravel their needs, lower the resistance to new ideas and persuade effectively. A criterion that they must have in influencing others is social responsibility. Social responsibility is the ability to show that one is a cooperative, contributing and constructive member of the social group (Stein \& Book, 2001). This component of interpersonal intelligence involves acting responsibly, even though they may not benefit personally, doing things for and with others, accepting others and using their talents for the good of the group, not just for himself or herself. This type of people may succumb to anti-social attitudes, act abusively towards others and take advantage of others.

\subsection{Ability to Tackle and Resolve Conflict}


Educators/lecturers should be able to resolve conflict or in another word, when an exceptional conflict resolves. They should figure out what is distracting the students and must be skillful in bridging the differences and working out creative resolutions to problems. This includes:

\subsubsection{Problem-Solving}

Problem solving is the ability to recognise and define problems, other than to generate and implement potentially effective solutions. Problem-solving is multiphase and it includes the ability to undergo a process of (1) feeling that there is a conflict, and feeling the belief and having the motivation that he or she can deal with it effectively; (2) defining and formulating the problem as clearly as possible; (3) generating as many solutions as possible; (4) making a decision to execute one of the solutions; (5) evaluating the outcome of the solution implemented; and (6) repeating this process if the problem persists. Problem solving is linked with being conscientious, and systematic in enduring with, and approaching problems. This skill is also linked with a desire to perform the best, and to confront problems, rather than to prevent them.

\subsubsection{Independence}

Independence is also linked with self-regard and the ability to tackle and resolve conflict. When they feel better about their own self, they will respect others and know how to tackle problems and conflicts that arise. Making solutions and acting upon them, followed with dealing with the effect, are important factors to success (Weisinger, 1998). The more they practice, the better they become and the higher the level of confidence will soar.

Independence denotes the ability to be self-directed and self-controlled in thinking and actions, and to be free from interpersonal dependency. Independent people are self-reliant when they plan and make crucial decisions. They seek for, and weigh other people's opinions before making the right decisions for themselves. The tendency to be independent rests in one's self-confidence and inner strength, and the desire to fulfill various expectations without having to succumb to them.

\subsection{Ability to Collaborate with Others Effectively}

Educators/lecturers work to materialise the group's goals more rather than their own. They need to know how to complement the styles of their students, coordinate the efforts exerted by team members and build consensus (Caruso \& Wolfe, 2001).

To collaborate with others effectively means seeking to find what strength can be adopted to attract others. First, making and sustaining friendships. Good, supportive friends are among life's greatest rewards. They are the people we turn to when we are happy and distress or simply companions, whom we share about life's everyday issues. The give and take of these vital relationships pays off in the short term, but the reward is great over time.

Educators/Lecturers have to start communicating, by identifying the cues which suggest that another person is interested to pursue the matter. Conversation then proceeds to invitation, beginning with non-committal activities. Present the invitation in a way that will enable them to gauge the other person's interest, perhaps by suggesting that they should meet up to do something, "sometime". A positive response means go, whereas a neutral one means he or she can try again some other day.

Secondly, it is the ability to resist negative events and stressful situations without falling apart, by actively and positively dealing with stress. This ability is based on (1) a capacity to go for courses of action for dealing with stress; (2) optimistic dispositions toward new experiences and change in general and toward your own ability to address the specific problem that you currently have successfully, and (3) a feeling that you can control or influence the stressful situation. Stress tolerance refers to being in possession of suitable responses to stressful circumstances. It is linked with the tendency to be composed, and to face adversaries calmly without being distracted by strong emotions. People with good stress tolerance tend to confront their crises rather than losing to the feelings of helplessness. Anxiety, which is common to emerge when it fails to function adequately, has a negative effect on general performance because it gives way to bad concentration, the difficulty in making decisions and several somatic issues.

\section{Conclusion}

Management educators need specific interpersonal skills to enhance their overall teaching effectiveness. This is due to the fact that students' personality is unique and complex to be understood. Thus, developing these skills demand understanding of one's own behavior and attitudes. Only then will they be able to possess the six abilities required to strengthen their own interpersonal intelligence. These tasks are imperative to make management education an interesting subject to be taught. 
Interpersonal and emotional intelligence solidifies the self-leadership and interpersonal relationships. Fortunately, it is a skill that can be mastered and developed by educators/lecturers. It can be classified as People Quotient (PQ). Educators/lecturers with high PQs are both flexible and resilient, having an inner core and a predominant approach of dealing with students, understanding that there are different strokes for different students. The six abilities discussed could serve as a basis to develop a highly intelligence person with regards to the interpersonal and emotional elements. These six types of abilities as have been mentioned earlier are crucial in ensuring the effectiveness of educators/lecturers in the field of management education.

\section{References}

Afolabi, O. A., Okediji, A., \& Ogunmwonyi E. (2009). Influence of emotional intelligence and need for achievement on interpersonal relations and academic achievement of undergraduates. Education Research Quarterly, 33(2), 15-29.

Caruso, D. R., \& Wolfe, C. J. (2001). Emotional intelligence in the workplace. In J. Ciarrochi, J. P. Forgas, \& J. D. Mayer (Eds.), Emotional intelligence in everyday life (pp. 150-167). Philadelphia: Psychology Press.

Cornersky, R. (1991). Implementing total quality management in higher education. Madison: Magnar Publications.

Gardner, H., Kornhaberm M. L., \& Wake, W. K. (1996). Intelligence: Multiple perspectives. Fort Worth: Harcourt Brace College.

Goleman, D. (1996). Emotional intelligence: Why it can matter more than IQ? London: Bloomsbury.

Gray, E. K. \& Watson, D. (2001). Emotion, mood and temperament: Similarities, differences and a synthesis. In R. L. Payne, \& C. L. Cooper (Eds.), Emotions at work (pp. 21-43). West Sussex: John Wiley.

Janis, S., \& Holly, S. (2005). How can university professors help their students understand issues of diversity through interpersonal and intrapersonal intelligence? Multicultural Education, 12(4), 20-24.

Killian, K... D. (2012). Development and validation of the emotional self-awareness questionnaire: A measure of emotional intelligence. Journal of Marital and Family Therapy, 38(3), 502-514. http://dx.doi.org/ 10.1111/j.1752-0606.2011.00233.x

Mayer, J. D. (2001). A field guide to emotional intelligence. In J. Ciarrochi, J. P. Forgas, \& J. D. Mayer (Eds.), Emotional intelligence in everyday life (pp. 3-24). Philadelphia: Psychology Press.

Mayer, J. D., \& Salovey, P. (1997). What is emotional intelligence? In P. Salovey, \& D. Sluyster (Eds.), Emotional development and emotional intelligence: Implications for educators (pp. 3-31). New York: Basic Books.

McBride, P., \& Maitland, S. (2002). The EI advantage: Putting emotional intelligence into practice. London: McGraw Hill.

Rowley, J. (1996). Motivation and academic staff in higher education. Quality Assurance in Education, 4(3), 11-16. http://dx.doi.org/10.1108/09684889610125814

Stein, S., \& Book, H. (2001). The EQ edge: Emotional intelligence and your success. United Kingdom: Stoddart Publishing Co. Limited.

Washington, M. C., Okoro, E. A., \& Okoro, S. U. (2013), Emotional intelligence and cross-cultural communication competence: An analysis of group dynamics and interpersonal relationship in a diverse classroom. Journal of International Education Research, 9(3), 241-246.

Weisenger, H. (1998). Emotional intelligence at work. San Francisco: Jossey- Bass.

Wong C. S., \& Law, K. S. (2002). The effect of leader and follower emotional intelligence on performance and attitude: An exploratory study. The Leadership Quarterly, 13(3), 243-274. http://dx.doi.org/10.1016 /S1048-9843(02)00099-1

\section{Copyrights}

Copyright for this article is retained by the author(s), with first publication rights granted to the journal.

This is an open-access article distributed under the terms and conditions of the Creative Commons Attribution license (http://creativecommons.org/licenses/by/3.0/). 